\title{
COLLECTIVE MEMORY-WORK AS METHOD AND RESISTANCE
}

\author{
Trisia Farrelly, ${ }^{1}$ Rochelle Stewart-Withers, ${ }^{2}$ Sharon McLennan, ${ }^{3}$ and \\ Lorena Gibson ${ }^{4}$
}

\begin{abstract}
Collective memory-work is a group method in feminist social research that involves the collective analysis of individual written memories. This method is well-established in educational research in Australasia, and yet it is curiously absent in social anthropology. Our memory-work collective experimented with this research method as a means of gaining a more nuanced understanding of our subjectivities as academic mothers employed by a neoliberal university in Aotearoa/New Zealand. Despite its potential weaknesses, we are convinced that collective memory-work as a research method can be valuable when all participants seek academic outputs, where power imbalances in the group are minimal, and where trusting relationships are pre-established. Our experiment with this method provided a context in which we could enact a feminist ethic of care to critically reflect on our positions as academic mothers in the neoliberal tertiary environment. We also regard the method as a form of 'feminist slow scholarship' offering a valuable opportunity to develop individual and institutional structural resistance.
\end{abstract}

Keywords: academic mothers; slow scholarship; feminist ethic of care; memory work; neoliberal university

\section{INTRODUCTION}

'Collective memory-work' as a group method in feminist social research has become well-established in educational research in Australasia. It involves the collective analyses of individual written memories (Onyx and Small 2001). While most social anthropologists rely on the interpretation of memories of past events to deepen understandings of the human condition (Bruner 2004), 
memory work as a research method is absent in social anthropology. The absence of this research method is particularly curious given the profusion of memory studies in anthropology: 'In every new anthropology publication there is another article about social, cultural, or material memory' (Berliner $2005,17)$. Categorised as 'memory work', 'collective memory', 'social memory', 'material memory', or 'cultural memory' (see for example, Candau 1998, and Climo and Cattell 2002 cited in Berliner 2005, 197), these terms have been employed by anthropologists, historians, and sociologists and denote 'the aggregation of socially framed individual memories and... collective phenomena sui generis' (Olick 1999, 333). 'Memory work' as a concept is most often referred to in the process of nation or identity construction (e.g. Litzinger 1998, 226). However, in this paper, we focus on 'collective memory-work' as a research method while also acknowledging that 'memory work as concept' and 'collective memory-work as method' share roots in subjectivity, intersubjectivity, and cultural/social construction.

In 2016, we, a group of four 'new and emerging' academic mothers, gathered for a weekend at a rented holiday house. Over the course of the weekend, we experimented with collective memory-work as a method. This paper presents our critical reflections on this method and our assessment of its methodological contribution to social anthropology's exploration of individual and collective academic subjectivities and resistance in academia. A series of memories emerged from this research retreat that highlighted some of the complexities New Zealand academic mothers may face in terms of promotion, leadership, and work/life choices in the neoliberal university. The critical reflection of these memories has inspired us to enact diverse strategies for individual and institutional structural resistance. We anticipate co-authoring papers that discuss these resistance strategies once we have determined their institutional impacts.

Some of the key themes that have emerged through these reflections on memory work as a method include balancing power, absences, and the desire to nurture. We conclude that, regardless of the potential weaknesses of the method as identified in the literature, these weaknesses can be addressed with imagination and innovation as originally intended by its creators, and that this method is particularly suited to the exploration of academic women's experiences. We particularly see its value in applied and feminist anthropology as its liberationist intent falls within the scope of a feminist Participatory Action Research (PAR). Collective memory-work can embody a feminist politics of resistance to time and resource constraints. It can also catalyse individual and collective resistance to a university that does not value a just, supportive, and 
collective work environment. As a research method, it is capable of producing rich raw data with the potential (given more time to think, talk, read, and write) to transform these into academic outputs. Collective memory-work then can be employed as a form of feminist 'slow scholarship' by which we resist 'unrealistic and counterproductive norms that have become standard expectations' (Mountz et al. 2015, 1253-1254) in the neoliberal academic regime. This feminist slow scholarship also allows us to develop strategies toward collective action by which we can (re)claim time to care for ourselves and others, and to revel in deep reflexive thought and engaged writing.

\section{Academic women in Aotearoa/New Zealand}

Our experiences as female academics in New Zealand universities provided the context for our memory-work foray. In 2014, the University of Auckland (2012) Equity Profile reported that women held only $26 \%$ of senior leadership roles, and that women represented only $22.4 \%$ of professors and $35.7 \%$ of associate professors. The 2012 New Zealand Census of Women's Participation found that women science researchers were under-represented in the Performance Based Research Fund ${ }^{5}$ (PBRF) and typically at a lower PBRF grade than their male counterparts 'regardless of their age or career stage' (Human Rights Commission 2012, 106). In seeking answers as to why women are underrepresented in academic leadership, literature on the subject has revealed that, perhaps unsurprisingly, women's experiences of academic life vary to men's due to differences in demands outside of work. For example, women report spending more time on housework, childcare, and eldercare than men, and they are more likely to have partners who work full-time (Misra et al. 2010). Moreover, women academics often take on roles within the university that are different to their male counterparts. Women spend more time in caring roles such as teaching, mentoring and service activities compared to male academics; with men tending to focus on research, an activity more likely to support their career advancement, and job security (Misra et al. 2010). Yet, these teaching, mentoring and service activities contribute little to the kinds of evaluations we are subjected to if we are to demonstrate our scholarly value in the neoliberal university - a fact reflective of the historical devaluation of women's time (social reproduction) and labour in caring roles since the $1900 \mathrm{~s}$ (Youngs 2001, 22).

\section{The memory-work collective}

We are four social science researchers: Aria, Jean, Liliana, and Cecelia. ${ }^{6}$ Aria invited the others to participate in the weekend retreat based on our com- 
monalities as early career academic mothers, our pre-existing collegiality, and the content of informal discussions over the years regarding our struggles as mother academics. Three of us had presented a panel on mothering and fieldwork at a conference and all of us had worked or studied together at some time. While shared experiences as academic mothers brought us together for the research, we are a relatively heterogeneous group. We are aged late thirties to late forties, two of us are social anthropologists and two draw on ethnographic methods in development studies. At the time of the research, our biological children ranged from two to fifteen years of age. One had a blended family of five children (two biological and three step-children) aged from eleven to seventeen years who resided fulltime in the household. Three of the collective were married: one with one child of primary school age and a husband who was unable to work full-time due to a disability; one with a pre-schooler; and one with two children aged seven and eleven. One cared for multiple dependents: an elderly and disabled mother-in-law; two exchange students; and her two children. Three of us are Pākehā (European) and one is a Pākehā-raised woman of Māori ethnicity; two identify as having a Catholic background but not (or semi-) practising, while another self-identifies as an 'open-minded agnostic atheist'. Some of us held permanent full-time positions, while others held tenuous short-term contracts.

In late 2014, our collective decided to explore the construction of our subjectivities as academic mothers in the context of tertiary academia in New Zealand. This was seen as timely given the competitive demands of the neoliberal university. These demands are currently quantitatively measured via the PBRF in New Zealand which calls for high number of high impact academic outputs; and an increased pressure to attract a greater number of international students and external funding alongside a new emphasis on student retention and completions. ${ }^{7}$ All of us struggled to meet the increasing demands of the standard academic teaching, service, and scholarship triad alongside our roles as mother/partner/daughter/colleague/friend. We all wanted to be 'good' working mothers (Buzznell et al. 2005), teachers, researchers, wives, community members, daughters, grandchildren, and colleagues. At the same time, we also struggled with the 'individual, hidden, and competitive' nature of the neoliberal university and its oppressive quantitative evaluations (Mountz et al. 2015, 1243).

The idea for a weekend retreat was strategic. We could not easily take long leave (Spronken-Smith et al. 2016) because of practicalities associated with commitments to our dependents and the peculiarities of funding requisites. We needed to develop innovative ways to research and publish. Collective 
memory-work, we hoped, would provide us with the purpose, the solutions, and the outputs we needed.

\section{COLLECTIVE MEMORY-WORK AS METHOD}

Collective memory-work (also known as 'collective autobiography') was developed in 1987 by sociologist and feminist, Frigga Haug and her collective in Berlin. Their first attempt at collective memory-work was a 1983 study of female socialisation, Female Sexualisation, published in 1987 with Haug as first author. The method was further developed after a visit from Haug to a group of academics in Sydney, Australia in the 1980s. This Australian academic collective employed the method in a published study of the social construction of emotion (Crawford et al.1992). Collective memory-work (hereafter referred to as 'memory-work') has since been applied across diverse academic fields (for example, teacher education [Ovens and Tinning 2009]; gender and women's studies [Bryant and Livholts 2007]; and environmental education [O'Donoghue 2006]). The philosophy in which the method is grounded is one of social constructionism as it is principally focussed 'on the process whereby individuals construct themselves into existing social relations' (Haug et al. 1987, 33). Memory-work aims to advance understandings of the ways in which individuals internalise dominant values; how dominant ideology can colonise individuals' relationships; and how individuals resist dominant structures and discourse.

The transformative goals of memory-work are principally aimed at enhancing capacity for collective action through critical individual and collective reflection, and theorisation which can then lead to individual and social change. Because memory-work as method holds the potential to make conscious 'the patterns of thought drilled into us by others' (Haug et al. 1987, 60), the action emerging from this conscientising ${ }^{8}$ is to cultivate 'strategies for liberation' and the development of resistances against this normality (Haug et al. 1987).

\section{The absence and value of memory-work as method in social anthropology}

Positivist researchers maintain the view that autobiographical memories are notoriously unreliable. However, memory-workers, like most social anthropologists, treat memories as the raw data through which the self and society are constructed. The interpretation of memory is less about how 'truthful' memories are and their accuracy as representations of past events. Rather, it is about how the telling of those memories can (re)construct those events (Crawford et al. 1992, 51). In this sense, memory-work is potentially transformative. 
Not only are our memories socially constructed; we also 'construct ourselves' in the process of memory making. Through our personal narratives, for the purpose of this paper, we construct and reconstruct our individual and collective identities as academic mothers. When we share these memories, we simultaneously contribute to a shared narrative. Thus, through collective memory-work, individuals may construct their experiences in a manner that facilitates subjective reflection. This allows us to make sense of life (Bruner 2004) and develop our identities (Kroger 2003). In the phases of memory-work as method, 'intersubjectivity precedes subjectivity' (Crawford et al. 1992, 52). In other words, meanings do not exist in the individual's head, but in relation to interaction with others and the common meanings found in this exchange (Halbwachs 1992). Memory-work adds innovative methodological value to traditional anthropological methods including narratives, life stories, and indepth interviews that can draw out the cultural construction of subjectivities.

\section{Revealing the biopower of the neoliberal university}

Many of those who study memory assert that we are most likely to recall significant life events because these are usually the ones that have the strongest emotional impact on us (Kippax et al. 1988; Ovens and Tinning 2009). However, in her memory-work, Betty Johnston found that rather than focussing on 'singular, extra-ordinary occurrences', her collective reflected 'layered' memories 'reflecting the ordinary repetitive stories of everyday life' $(2001,1)$. These layered memories represent what Johnston calls 'the texture of the everyday' $(2001,36)$. Regardless of whether women write memories of the mundane and every day or of extraordinary events, the stories that they tell are significant and worth telling.

Foucault's (1973) 'biopower' describes the regulation of populations and the disciplining of bodies by modern social institutions within a capitalist economic system through what Foucault calls 'the normalizing technologies of power and self'. 'These technologies are most efficient and effective when individuals take up the task of self-regulation and self-disciplining, something that occurs as persons take up identities offered them through the discursive practices of social institutions and professions' (Jaye et al. 2006, 141-142). Bourdieu (1977) would describe these technologies as 'doxic' or 'taken for granted'. One of the strengths of memory-work is its potential to help us remember the everyday mundane in order to explore this 'barely perceived ordered daily training in normality' (Haug et al. 1987, 90). Biopower becomes so naturalised that we cease to question the identity our institution constructs for us, nor our institution's expectations of us, nor the expectations we create for ourselves as 
a result. We simply accept all of this as 'just the way it is' - our 'burden to bear'. It is perhaps only through the remembering and collective theorising of the mundane that even the most naturalised of the corporate university's technologies of regulation and discipline can be revealed. In so doing, empowering strategies may be collectively actioned to resist such technologies.

\section{A flexible three-phase approach}

While they provide a series of steps and 'rules' for doing memory-work, Haug and her colleagues emphasised that there are no prescriptive requirements for employing the method: 'What we need is imagination. We can, perhaps, say quite decisively that the very heterogeneity of everyday life demands similarly heterogeneous methods if it is to be understood' (Haug et al. 1987, 70-71). In 1992, Crawford and her memory-work collective expanded on and made more explicit the guidelines provided by Haug et al. (1987). The result was a threephase account of memory-work and some general principles for those seeking to use it as a method. Remaining true to the original intention of this method, we decided to follow the broad principles and steps of the memory-work method as outlined by Crawford et al. (1992) while also remaining flexible and responsive to the needs of the members of the collective (Haug et al. 1987).

The three phases of memory-work will next be outlined and contextualised through our own rendering of these over the course of the research retreat. Broadly, the three phases are i) writing the memory; ii) collectively theorising the memory; and iii) further theorisation by the researcher or collective. These phases were not revealed in any detail to the collective prior to the retreat as Aria wanted each member to avoid preparing, editing and theorising their responses in advance.

\section{Phase one - Writing the memory}

On the first day of the two-day retreat, we all took time to settle in, then made the fire and ate together. Aria referred to the information sheet, consent forms, aims and method (all sent by email a month before). She re-emphasised the collaboration of the method before leading a 'safety briefing. While in some ways similar to Koutroulis' (1993) 'setting the agenda,' our 'safety briefing' was not the product of our critical reflection on the theorisation stage; it was a defined additional phase that preceded Crawford et al's (1992) 'phase one.' The principle aim of this additional phase was to ensure the retreat was collectively constructed as a safe space to share potentially emotional memories (Farrar 2001). During this phase, we agreed on the research aims, ethics, and phases. It 
was also an opportunity for everyone to air any anxieties or concerns.

Aria asked if everyone was comfortable following Crawford et al's (1992) suggested techniques for the first phase:

Write 1-2 pages about a particular episode, action or event (the 'trigger'/'cue' ${ }^{9}$ ).

Write in third person using a pseudonym.

Write in as much detail as possible.

Describe the experience: do not interpret or explain.

We agreed that whatever we decided to do, everyone would discuss how they were feeling and progress accordingly through collective negotiation. Collective consensus was that the process should be predominantly organic rather than prescriptive. During the first phase, Aria invited the collective to individually write down a memory of a particular experience. The cue was 'a struggle or challenge related to their identity as academic mothers'. None of the cues were provided to the collective before the retreat as Aria did not want the participants to have time to edit or theorise their memories prior. One member of the collective did not identify herself as a 'mother' but more specifically as 'Alice's mum'. Therefore, the wording of the cues needed to be broadened to accommodate a referent with which this co-researcher could identify. This highlights the need for the core concepts to be carefully negotiated from the outset to ensure all members of the collective are 'on the same page'. Finally, the second and third cues were confirmed as meaningful for the whole collective.

Writing down the memory is critical as the very act of writing it in a visible and reportable form affords a level of significance to the memory - even those memories that initially appear to be the most mundane. We did not limit ourselves to page numbers as recommended by Crawford et al. (1992). Instead, a time of twenty minutes was set in the first instance. For the next cue, suggestions were requested regarding the duration. Memory-workers recommend writing in the third person as it may help the writer avoid justification for actions associated with the memory. It also provides some objective distance between the memory-maker and the event. While we aimed to write our memories in the third person, this took some getting used to. Some of us preferred to use the first person when responding to the first cue but by the time we were writing memories in response to the third and last cue, two of us were writing 
in the third person. Liliana, however, continued to struggle throughout the retreat with the third person perspective. Here she explains why:

I completely owned the memories and felt more comfortable expressing them as they were. . coming from me; about me... I was in the moment. I wasn't someone else looking in on someone else's experience... looking down on it as though it were someone else. That would feel too detached for me.

Jean also diverted from the third person narrative assumed in memory-work to write a poem. When asked why she chose this style of writing in her memory-work she responded,

I... had recently attended a workshop by Kirin Narayan where she had us do an exercise that involved writing a piece of poetry... [T] he prompt she gave us from her book Alive in the Writing was great and I enjoyed the exercise. The prompt... for the last exercise was similar to Kirin's exercise, and I just happened to have her book with me, so I flicked to the page to make sure that it looked like it would work. It did.... Also, I feel like we were all starting to produce narratives similar in style as happens when you like what you hear of others' writing and shape your own work in response, and I wanted to change things up a bit. I think it complemented the narratives that everyone else produced. I would call what I wrote a piece of ethnographic poetry.

As mentioned, the protocol described above recommended that we all tried to write in as much detail as possible and to limit ourselves to descriptions of our selected event rather than lapse into interpretation or explanation. This ensured that the writing of one contributor emplaced the rest of the collective into that writer's shared memory. This level of detail also increases the capacity for others to empathise with the memory, thus making it more accessible for collective theorisation.

\section{Phase two - Collectively theorising the memory}

In phase two, the collective took turns to read their memories aloud. This was followed by a group discussion about the memory. This stage captured the duality of self: 'the self talking with itself' [phase one] and then 'responding to itself as others respond to it' [phase two] (Crawford et al. 1992, 40). Crawford et al. $(1992,49)$ offer a six-point procedure for this phase: 
Everyone in the collective has the opportunity to respond to each written memory.

Commonalities are sought between the memories.

Markers are identified for the taken-for-grantedness of social explication of the meaning of recurring events such as clichés, cultural imperatives, contradictions, and generalisations.

Literature, popular symbolisms, and interpretations of the memories are drawn on to, again, find common ground in social explication of the meanings of the memories and the way they relate to the cue/ topic.

Silences are interrogated, exploring also what was not said, yet could have been, and the reasons for these omissions.

The memory may be rewritten.

Our collective did not systematically proceed through the phases of this sixstep procedure as doing so felt too prescribed and rigid. Instead, the direction of the theorisation of each narrated memory took on a life of its own. While we did respond to each of the memories one by one, each of the co-researchers responded in any way they felt relevant and meaningful. The collective allowed the research process to be driven by our responses to the cues and the conversations that naturally flowed from these. When asked about this later, Liliana described feeling a little lost due to the organic manner in which the theorising unfolded. However, Jean and Cecelia were glad they did not systematically go through the six-step procedure. For example, Cecelia stated, 'Once we had been through the first session and I could see how it worked, I found myself relaxing and enjoying the experience. The flexible approach helped with this'. The analytical advantages of this approach was that it opened up more opportunities for the discovery of new and unanticipated reflections and realisations.

\section{Phase three - Further theorisation}

Phase three occurs on completion of the raw data-gathering phase. The material provided from the written memories and collective theorisation from the retreat is further theorised either by the principal researcher or collectively. This was a recursive process whereby the common threads were related back to earlier discussions and to the broader literature. The final draft is subject to 
further discussion by the collective. During our final session at the retreat over afternoon tea, we all confirmed that we would like to co-author all the work generated from the retreat.

EXPERIMENTATION WITH THE METHOD: EMERGENT THEMES

Following a series of phone and Skype calls, face-to-face discussions, and emails, three methodological themes emerged from our experimentation with memory-work as method: power, silence as absent presence, and nurturing. These themes comprise our contribution to the development of collective memory-work as a method for social anthropology. They are also pertinent contributions for any methodological framework employed by social anthropologists.

Power

Many who find any weakness in memory-work as method refer to the problem of power. The goal of memory-work and PAR is that all participants, including the principal researcher are considered co-researchers (Khan and Chonavec 2010) and thus co-constructors of knowledge. This requires the collapse of subject and object. As Haug et al. (1987) states, collective memory-work is only possible if the subject and object of the research is one and the same person. However, many who have carried out memory-work concede that, regardless of best intentions, the principal researcher almost always holds a greater share of the power. Conversely, the absence of a dedicated lead researcher has its own problems in terms of catalysing discussion, ensuring the process remains more or less on task, bringing the discussion to a close, and summarising decisions. Even though they were all seasoned memory workers, Cadman et al. (2002, 5) 'experienced significant tensions inherent in working with a method that requires "going against the grain" of "research-as-usual"':

We felt responsible for the success of the event, but often could not or would not control the discussion. There were contradictions and ambiguities in being, and desiring to be, at once powerful-not powerful, controlling-open, traditional-creative, hierarchical-collaborative, and objective-subjective. These contradictions appeared at times to be mediating against the researcher's intention to be and to experience the method as, collaborative and participatory.

However, as Jean states, 'Even if the principal researcher does take a leadership role, this does not inevitably lead to the diminished power or agency of the 
other members of the collective. Sound leadership or facilitation can produce positive and empowering experiences for a collective. For example, Liliana and Cecelia described the relief they felt when they learned for the first time that they did not have to lead the research or writing project but could still participate fully and publish out of the experience. Cecelia added that the collaborative nature of the research method and the outputs meant that she was able to publish from the research while fulfilling other work commitments.

This is not always the case, as noted in the experience of Glenda Koutroulis (1996). Koutroulis conducted memory-work with others who were not all academics/researchers. Hers was an academic endeavour that was not shared with her collective. Her memory-work was also conducted where prior knowledge of theorising did not exist and was not generated. This culminated in divergent goals for the members of the collective. As one of her participants stated, 'It's primarily your needs that are being met... You're the one who wants to do the $\mathrm{PhD}$. You're the one who needs the data... Let's be real about it' (Koutroulis 1996, 84). Conversely, our memory-work collective shared our early career academic status as well as motherhood. The collective shared power because of our experience in working with theory, our willingness to co-construct knowledge, and our common goals. The common goal of academic outputs was provocative. Particularly appealing was the possibility that these publications might contribute to positive social change for academic mothers while also enhancing our own self-worth, creativity, and passion for our work.

\section{Silence as Absent Presence}

Crawford et al.'s (1992) six steps in phase two of memory-work suggest the collective interrogation of silence as 'absence' (Farrelly 2014). We have learned from our own fieldwork/research experiences that absence can be made present and can be traced through thoughts, emotions, and material objects (Farrelly, Stewart-Withers, and Dombroski 2014). Via various kinds of places, objects, and practices, the absent can have an important effect on the social world - in other words, absence has agency (Meyer 2012,107). 'Yet absence is not only something that does. Absence is also something we engage with, something we do something to' (Meyer 2012, 104, original emphasis).

Absences imply agency in memory-work when individuals consciously decide to omit information from their narratives. Regardless of the conscious or unconscious decision to omit information, these absences are also agentive if the collective can identify these absences. While cues can prompt the remembering of events that may have been forgotten, as Jean illustrates, if participants 
are to maintain control over their contribution to memory-work, they must feel free to withhold information: 'One of the writing exercises we did helped me remember an aspect of an experience that I had forgotten. I also chose not to write about certain experiences because I'd quite like to forget them!'

Cecelia describes herself as 'generally quite private'. As such, she found the preparation for the retreat and the first phase 'a little unnerving. Like Jean, there are some things Cecelia would normally choose to forget: ' $\ldots$ there are things I don't want to remember or to spend time thinking and talking about'. Liliana agreed:

... not all absence needs to be problematised for the purpose of making present. Appreciating the gaps and indeed the silence that the method affords one is useful. We don't get to be silent often. The PBRF has no use for silence or absence. It is all about making sure you have presence: if it is not obvious then interrogate the space until it is evident. You're constantly looking to produce the evidence and talk up the ordinary. The PBRF is about demonstrating your position of esteem. Using this method allowed me the space, silences, and time I needed to think and then talk through what we do, how we do it and why, with other mothers who similarly struggle with maintaining a PBRF-life balance.

While these absences can be intentional, sometimes what has not been articulated or 'glossed over' can alert the collective to the 'taken-for-grantedness' of dominant structures of power. One of Foucault's (1972) principles for discourse analysis is 'the principle of reversal' which calls us not to look for what the discourse conveys, but for what it excludes. These absences could indicate the presence of self-disciplining technologies that normally pass by unnoticed.

Interrogating silences, where appropriate, may reveal the hegemonic masculine discourses that have become naturalised in the neoliberal university. These discourses can effectively marginalise 'women and those men who identify with different forms of masculinity, or indeed, with characteristics more closely associated with forms of femininity' (Atkins and Vicars 2016, 252). In the absence of time and opportunity for regular collective and critical reflections of these technologies, academic mothers may have little chance of liberation from them.

\section{Nurturing}

The desire to nurture was a recurring theme in the stories we shared about our 
roles as mother academics over the weekend. This desire reflects a feminist ethic of care. Feminist care-focused ethics makes more visible the tendency for the neoliberal university to devalue the ways in which women academics are motivated to work, think, and write. We recognised that self-care and othercare was important. Care of ourselves and concurrently care of one another is a political and transformative act (Lorde 1988). Referencing Audrey Lorde, Sarah Ahmed writes,

Self-care: that can be an act of political warfare. In directing our care towards ourselves we are redirecting care away from its proper objects, we are not caring for those we are supposed to care for; we are not caring for the bodies deemed worth caring about. And that is why in queer, feminist and anti-racist work self-care is about the creation of community, fragile communities, assembled out of the experiences of being shattered. We reassemble ourselves through the ordinary, everyday and often painstaking work of looking after ourselves; looking after each other. This is why when we have to insist, I matter, we matter, we are transforming what matters. Women's lives matter; black lives matter; queer lives matter; disabled lives matter; trans lives matter; the poor; the elderly; the incarcerated, matter. (2014, para 40)

For memory-work to offer a potentially emancipatory and transformative experience, participants must feel nurtured at every stage. Cadman et al. (2002, 11) reflect on the need to nurture in their own memory-work:

Typically, we, as feminist researchers, felt compelled to invest time and energy into providing a nurturant atmosphere. Frequently this meant engaging in obvious, taken-for-granted practices of nurturing such as the preparation and presenting of food.'I spent so much time and energy on the bloody food it was ridiculous'.

Like Cadman and her collective (2002), food played a vital role in creating an atmosphere that was conducive for our memory-work retreat. For Aria, the compulsion to nurture started about a month before the retreat, ensuring everyone was happy with the accommodation location, that dates and times of arrival and departure worked for each woman's life schedule, and that everyone was comfortable with the proposed loose structure of the retreat. Once at the retreat, there was a gentle respect for one another's wellbeing. Simple acts of nurturing were regularly and spontaneously expressed throughout the weekend. These acts included expressions of concern and empathy when 
women became emotional during the sessions, the fire lit by the first to rise in the morning, heaters turned on in bedrooms for others, and food preparation. Nurturing also involved allowing others to share their memories however they chose to, and allowing members to exercise their right to silence.

Nurturing is a key criterion for generative women's groups (Butler and Wintram 1991; Keller and Moglen 1987; Kippax 1990). The need to nurture was inextricably linked with the collective desire to build trust, be reciprocal, and enact support. Trust as key to the success or failure of memory-work has been linked to debates around familiarity between collective members. While there are no rules as to how to recruit a memory-work collective, there are two schools of thought on the matter: one argues that the more heterogeneous the group, the more wide-reaching the insights regarding socialisation (Crawford et al. 1992; Haug et al. 1987); the other argues for a group of ready-formed relationships, suggesting a more homogeneous group (Kippax 1990). While our collective shares some experiences as mother academics, our life experiences are diverse. However, our collective is based on prior work/study relationships and we trust one another with our contributions to the research. Small (1999) cautions, however, that the more intimate the relationship between the researcher and the researched, the more likely a group member will divulge more than they may later feel comfortable with, thus raising the likelihood of ethical dilemmas. Moreover, while memory-work aims for emancipation and positive social change for its participants, these can never be guaranteed and, for some, the experience may be too confronting and exposing.

Memory-work is not only about individual emancipation; it is also about broader social change. Sometimes this higher goal has a personal cost which some participants may feel is too great (Koutroulis 1993). While mindful of some of the ethical pitfalls of conducting memory-work as method, our preestablished high degree of trust, mutuality, reciprocity, and support was something the collective felt would overcome most ethical dilemmas that might arise.

Because we all knew each other, I felt comfortable and safe, and able to be open and honest. I trusted that I could choose to participate as much or as little as I wanted, and that I had a say over how things I said would be used. I also feel like I have the ability to say, 'don't use this thing I mentioned' after the fact, and trust that it won't be used. (Jean)

I did feel a bit apprehensive, but that was balanced with the fact we 
already knew each other well and there was a high level of trust. I don't think it would have worked without that initial basis of trust. (Cecelia)

The trust established prior to, and during the retreat was an important element in power-sharing and participation. As co-producers of the research, each member of the collective knew that she could edit or include data at any time to ensure satisfaction with their contribution to the research.

Like Small et al. (2011), we found that New Zealand's performance-based tertiary education system challenged our ability to meet all the responsibilities of our multiple roles at work and in our personal lives. Some of us also noted the difficulty of fulfilling our need to nurture our students and our own intellectual and collegial needs while also responding to the seemingly relentless pressure to produce high impact publications (Berg and Seeber 2016). The memory-work method provided an opportunity for us to make some progress in at least one of these areas and we experienced this as empowering.

\section{CONCLUDING REMARKS}

Our collective memory-work constitutes participant-observation. As Tim Ingold (2000, 108) reminds us, anthropologists 'know' through 'being' with our participants in participant-observation: 'Indeed, there can be no observation without participation - that is, without an intimate coupling, in perception and action, of observer and observed. Through participant-observation, we also learn about ourselves. Our collective memory-work involved participants with whom long-term relationships had been forged around a shared experience: academic motherhood. We have all known one another for over a decade and most of us have been in academia this long as students and lecturers. We have developed a level of familiarity with one another's personal and professional struggles and celebrations that touch on our lives as academic mothers. Our physical and purposeful convergence for a weekend research retreat provided fertile space for the production of auto-ethnographic and ethnographic data and yet the conversations continued long after the weekend was over via phone calls, emails, and back in the hallways.

All those who participate in memory-work are at once observer and observed. There is no question of a participant either 'being' (that is, an active participant in the research), or 'knowing' (as an outside observer theorising their observations). All involved in memory-work co-constitute the knowing and the being. The knowing is perhaps arguably more fluid in memory-work than 
in traditional ethnographic fieldwork because the 'knowing' requires greater self-reflection through full participation. For example, each member of the collective may move from 'knowing' from our memories and our 'being' (our participation in our own experiences) to a sense of more or less certainty in our interpretation of them when shared and theorised with the collective. From self-reflection and collective meaning-making we may build a greater selfawareness of our subjectivities, and a deeper appreciation of others' memories and the institutional structures and processes that inform us.

\section{Memory-work as transformative action}

In this way, memory-work can be seen as a mechanism for reflective practice (Schön 1983) whereby collective members can enhance developmental insight. For example, the memory-work retreat provided Jean a rare opportunity to collectively and critically reflect on how she balanced her academic career with her role as wife and mother. She emerged from the research retreat with greater clarity regarding what she and her family wanted and needed, describing the weekend as 'transformative':

For weeks after the retreat I found myself reflecting on the themes that arose in our narratives, particularly our discussions about how to negotiate relationships and balance family life with the demands of the job. I took up my current position straight after completing my doctorate so I applied the work habits I had developed to finish the thesis to my new job, without stopping to think about how extreme they were. I didn't slow down after my daughter was born either, instead sacrificing sleep so I could work into the wee hours of the morning and on weekends. Of course this was not good for me, my husband, or my daughter. Talking about these work habits and the negotiations that take place in relationships ('if I work on Saturday we can spend Sunday together...') with others in similar situations was a transformative moment for me. I still feel like I have to work long hours to increase my chances of securing a permanent academic position, so I do work on some weekends and for an hour or so some evenings. However, I have reduced these hours and, after hearing how others in the collective prioritise various tasks, changed what I'm working on. Now when I work at home I do so only on projects that will benefit my career if I need to look elsewhere for a job - such as writing my book - rather than writing lectures or administrative work. 
While the ethic of care as 'warfare' motif described by Ahmed (2014, para 40) was absent from our discussions, in hindsight, we can now see how we can support our women academic peers and students to deploy a feminist slow scholarship. We believe a feminist slow scholarship is a potent contribution to an arsenal of resistance against the neoliberal university's ever-increasing demands on our time, our emotions, and our bodies. Two of us are now committed to developing a feminist slow scholarship as collective action at our own university. This will involve following some of the strategies for collective action offered by Mountz et al. (2015) including giving workshops and seminars on feminist slow scholarship, organising writing retreats and support groups for postgraduate students, and valuing time to think.

\section{Weaving a collective memory}

Memory-work as a version of PAR acknowledges the marginalisation of women and gender in early participatory research (see Maguire 1987). We aimed to embody Reinharz and Davidman's (1992) key feminist PAR features in this research. These features ensure women are empowered in the research process and that the research distributes information that is capable of changing others' actions. This kind of liberationist research '... changes the researcher, sometimes painfully, sometimes in exciting and sustainable ways. The self-reflexivity such changes engender is a feature of all feminist scholarship in some way' (Gatenby and Humphries 2000, 90). For Reinharz and Davidman (1992), a feminist PAR approach should endeavour to create new relationships and improved institutions. The research process should also demystify research so that its political consequences can then be made available to all women (Reinharz and Davidman 1992). As a liberationist method, memory-work holds the potential to promote social change in the lives of academic women by providing opportunities for 'consciousness-raising' to 'clarify the steps necessary to gain access to opportunities in the educational system (and hopefully in the larger society)' (Spindler and Spindler 1993, 29). Our research may be seen as an intervention by providing the opportunity to critically reflect on gender roles, identity, relationships, and how broader structures including educational institutions construct our subjectivities as academic women and mothers, and by promoting the social reconstruction of systemic injustices (Fendler 2003).

Phases two and three of the method involved collective social analyses. If memories are socially constructed, those who inhabit the same or similar social fields will share similar dominant values, ideologies, structures and discourses. Memory-work has the potential to reveal these thus rendering them 
available for inspection and transformation. The collective theorising phases of memory-work involve weaving (Kippax et al. 1988) the threads and traces of women's individual memories into a collective memory. This process of weaving may foreground the doxic or taken-for-granted dominant structures of academic life and how these dominant structures influence the ways we self-identify as mothers and academics. 'In making conscious the material out of which we have made ourselves ... we are creating conditions for a more resilient fabric for our lives' (Haug et al. 1987, 49). Thus, we as academic women, can be seen to weave our relationships and to re-weave our lives through memory-work (Farrar 2001).

\section{CONCLUSION}

We see memory-work as a work-life strategy, an example of feminist slow scholarship, and as a potentially powerful example of collective action. We will employ the strategies that we have learned from each other through the deployment of this method in ways that will allow us and others to use time to nurture ourselves and others, and to simultaneously resist unsupportive institutional structures and discourses. The method also offered us the time to consider meaning in our lives in a nurturing environment through self-reflective silences, spoken memories, and critically reflective conversations. This helped us to re-evaluate our priorities and consider how to better communicate our needs to family, colleagues, friends, and managers. Memory-work also has the potential to be a highly generative research method providing each member the opportunity to lead author a publication from one of the key themes that emerged from our weekend research retreat. Multiple publications could potentially originate from one weekend retreat or from additional retreats. The method has provided us with a strategy by which we can respond to PBRF demands.

Some might consider our application of this method as mercenary in terms of its intent to maximise outputs while minimising the research effort. Rather, we see the method as a rational response to the relentless and masculinist managerial pressures of the neoliberal university. Future memory-work retreats were inspired once the normalised discourses underpinning these pressures were collectively revealed through the method. We also consider our collective response as a political one. Atkins and Vicars (2016) extend the 'absent presence' we refer to in this paper to the absent presence of women in educational leadership. They attribute this absent presence to the masculinisation of 'social relations, cultural models, power and politics, perspectives on experience, values and attitudes in the neoliberal university' (Atkins and Vicars 2016, 11). Our 
memory-work collective exposed the dominant masculinist, competitive and individualistic principles underpinning the academy.

The irony of sacrificing our personal/family time in the weekends to 'work' to produce research outputs to respond to PBRF demands, and to reflect on/ reweave our work/lives has not escaped us. What this tells us about our academic subjectivities is that the impact of current work demands is high and that the possibilities open to us for resistance are limited. Ania Loomba (2003, 257) argues that human agency 'cannot be idealised as pure opposition to the order it opposes; it works both within that order and displays its own contradictions. This paper is fundamentally contradictory - and yet it is not. While the weekend was work; it was also catharsis, time to think, and an opportunity to offer and receive care from those who best understand the challenges we face as academic mothers. It was also an opportunity to 'escape' from the demands of our work and our home responsibilities. This was less work and more pleasure because as a group we enjoy each other's company. Given the time to write differently, we enjoy writing. Given the time and space, we can think and produce quality work as a result. Our resistance and liberation was realised as a mutually supportive, collegial, and cathartic experience: entirely in opposition to our current fast-paced, individualistic, and competitive tertiary education culture. Time will tell if the future publications we generate from our collective-memory work and the additional strategies we deploy will improve our universities and our place in them.

\section{ACKNOWLEDGEMENTS}

We would like to acknowledge our families for their love and support.

\section{NOTES}

1 Trisia Farrelly is a senior lecturer of Social Anthropology and Environmental Management at Massey University, New Zealand. She is the Co-Director of Massey University's Political Ecology Research Centre; she is on the Steering Committee of the New Zealand Product Stewardship Council (NZPSC) and the environmental lobby group, Carrying Our Future; and she is the Massey University representative for the Association of Social Anthropologists Aotearoa New Zealand. Her current research interests include qualitative methodologies; new materialisms and political ecologies of plastic production, consumption, and disposal; social license to operate (marine industries); and protected area management.

Email: t.farrelly@massey.ac.nz 
2 Dr Rochelle Stewart-Withers is a senior lecturer in Development Studies. The focus of her teaching and research looks to understand and analyse/critique processes that are transforming people's lives around the world, with a particular focus on the world's poorer countries. Current research looks at the way sport is used to achieve social and economic goals in developing countries and/or marginalised communities with a focus on the Pacific Region. Rochelle is also Chair of her University's Ethics Committee, hence other areas of interested are ethics, methodology, and complexities of fieldwork. Rochelle is also a board member of the NZ Mental Health Foundation, and she mothers six teenage children.

Email: r.r.stewart-withers@massey.ac.nz

3 Sharon McLennan is a lecturer in Development Studies at Massey University in Palmerston North. Her research interests include the conceptualisation of global citizenship in higher education in New Zealand, South-South cooperation in health and development, international volunteering, and social media in development.

Email: s.mclennan@massey.ac.nz

4 Dr Lorena Gibson is a lecturer in Cultural Anthropology at Victoria University of Wellington. She specialises in the anthropology of development with an area focus on Melanesia, South Asia, and Oceania. Her research focuses on processes of development and social change, how social actors relate to the future, education and liberation, the politics of hope and agency in vulnerable urban spaces, and creative artistic practices.

Email: lorena.gibson@vuw.ac.nz

5 The Performance Based Research Fund (PBRF) is a New Zealand tertiary education funding assessment process. The PBRF assesses the research performance of tertiary education organisations (TEOs) and funding is distributed accordingly.

6 Pseudonyms are provided for contributors throughout.

7 The New Zealand Tertiary Education Commission (TEC) allocates the Government's contribution to the direct costs of teaching, learning and other costs. The TEC determines the amount of funding a TEO receives through Investment Plans. While historically there has been a focus on enrolment numbers, there is now a shift of focus on 'successful course completion' (scc). Hence, those courses labelled 'low performing papers' (LPP) are at risk of losing funding. While students may not complete or fail courses for many reasons, academic staff are now compelled to work beyond the requirements of their contracts particular in terms of pastoral care (and sometimes sacrificing fairness to all students for 
example in offering extra [and extraordinary] extensions for assignments), to retain students and thus funding.

8 Enactment of critical consciousness (see Freire 1974). Friere's 'conscientising' is at the core of PAR.

9 We use the term 'cue' as opposed to Crawford et al.'s (1992) 'trigger' because 'cue', to us, implies an invitation to respond consciously and in due course; whereas 'trigger' suggests a demand to respond immediately and the production of an unconscious reflex.

\section{REFERENCES}

Ahmed, Sarah. August 25, 2014. 'Selfcare as Warfare', Feministkilljoys (blog), https:// feministkilljoys.com/2014/o8/25/selfcare-as-warfare/

Atkins, Liz and Mark Vicars. 2016. 'Feminine Men and Masculine Women: In/exclusion in the Academy'. Education + Training 58 (3):252-62.

Berg, Maggie, and Barbara Karolina Seeber. 2016. The Slow Professor: Challenging the Culture of Speed in the Academy. Toronto: University of Toronto Press, Scholarly Publishing Division.

Berliner, David C. 2005. 'The Abuses of Memory: Reflections on the Memory Boom in Anthropology'. Anthropological Quarterly 78 (1):197-211.

Bourdieu, Pierre. 1977. Outline of a Theory of Practice. Cambridge: Cambridge University Press.

Bruner, Jerome. 2004. 'Life as Narrative'. Social Research: An International Quarterly $71(3): 691-710$.

Bryant, Lia, and Mona Livholts. 2007. 'Exploring the Gendering of Space by Using Memory Work as a Reflexive Research Method'. International Journal of Qualitative Methods 6 (3):29-44.

Butler, Sandra, and Claire Wintram. 1991. Feminist Groupwork. London: Sage.

Buzzanell, Patrice M., Rebecca Meisenbach, Robyn Remke, Meina Liu, Venessa Bowers, and Cindy Conn. 2005. 'The Good Working Mother: Managerial Women's Sensemaking and Feelings about Work-Family Issues'. Communication Studies 
$56(3): 261-85$.

Cadman, Kate, Lorraine Friend, Susanne Gannon, Christine Ingleton, Glenda Koutroulis, Coralie McCormack, Patricia Mitchell, Jenny Onyx, Kerry O’ Regan, Sharn Rocco, and Jennie Small. 2002. 'Memory Workers Doing Memory-Work on Memory Work: Exploring Unresolved Power'. http://researchonline.jcu.edu. au/11817/1/Kate_Cadman_et_al_memory_workers.pdf

Climo, Jacob, and Maria Cattell, eds. 2002. Social Memory and History: Anthropological Perspectives. Walnut Creek, California: Rowman Altamira.

Crawford, June, Susan Kippax, Jenny Onyx, Una Gault, and Pam Benton. 1992. Emotion and Gender: Constructing Meaning from Memory. London: Sage Publications.

Farrar, Patricia. 2001. 'Too Painful to Remember: Memory-work as a Method to Explore Sensitive Research Topics'. In Memory-Work: A Critique. Working Paper Series, 20/o1, edited by Jennie Small and Jenny Onyx, 1-11. Sydney: School of Management, University of Technology. https://opus.lib.uts.edu.au/research/ bitstream/handle/2100/414/Patricia\%2oFarrar.pdf?sequence $=1$

Farrelly, Trisia 2014. 'Silence/Absence as Passive Resistance in Fiji: A Case Study of Indigenous Ecotourism Development in Taveuni'. Micronesian Educator 19: $48-58$.

Farrelly, Trisia, Rochelle Stewart-Withers, and Kelly Dombroski. 2014."Being there”: Mothering and Absence/Presence in the Field'. Sites: A Journal of Social Anthropology and Cultural Studies 11(2):25-56.

Fendler, Lynn. 2003. 'Teacher Reflection in a Hall of Mirrors: Historical Influences and Political Reverberations.' Educational Researcher 32 (3):16-25.

Foucault, Michel. 1972. The Archaeology of Knowledge. Translated by A.M. Sheridan Smith. New York: Pantheon Books.

- 1973. The Birth of the Clinic. Translated by Alan Sheridan, London: Tavistock.

Freire, Paolo. 1974. 'Conscientisation'. CrossCurrents 24 (1): 23-31.

Gatenby, Bev, and Maria Humphries. 2000. 'Feminist Participatory Action Research: Methodological and Ethical Issues'. Women's Studies International Forum 23 (1): 89-105. 
Haug, Frigga. 1987. Female Sexualization. Translated by Erica Carter. London and New York: Verso.

Halbwachs, Maurice. 1992. On Collective Memory. Chicago: University of Chicago Press.

Human Rights Commission. 2012. New Zealand Census of Women's Participation. https://www.hrc.co.nz/files/2314/236o/5171/web-census.pdf

Ingold, Tim. 200o. The Perception of the Environment: Essays on Livelihood, Dwelling, and Skill. London: Routledge.

Jaye, Chrystal, Tony Egan, and Sarah Parker. 2006. “Do as I say, Not as I do": Medical Education and Foucault's Normalizing Technologies of Self.' Anthropology and Medicine 13 (2): 141-155.

Johnston, Betty. 2001. 'Memory-Work: The Power of the Mundane'. In MemoryWork: A Critique, Working Paper Series, 20/o1, edited by Jennie Small and Jenny Onyx, 1-11. Sydney: School of Management, University of Technology. https:// opus.lib.uts.edu.au/research/bitstream/handle/10453/19756/Betty\%20Johnston. pdf? sequence $=1$

Keller, Evelyn F., and Helene Moglen. 1987. 'Competition and Feminism: Conflicts for Academic Women'. Signs 12 (3): 493-511.

Khan, Candy and Donna Chovanec. 2010. 'Is Participatory Action Research Relevant in the Canadian Workplace?' Journal of Contemporary Issues in Education, $5(1): 34-44$.

Kippax, Susan. 1990. 'Memory Work: A Method'. In The Social Sciences and Health Research, edited by Jeanne Daly and Evan Willis, 93-97. Canberra: Public Health Association of Australia.

Kippax, Susan, June Crawford, Pam Benton, Una Gault, and Jenny Noesjirwan. 1988. 'Constructing Emotions: Weaving Meaning from Memories'. British Journal of Social Psychology 27 (1):19-33.

Koutroulis, Glenda. 1993. 'Memory-work: A Critique'. Health Sociology Review $3(1): 76-96$. 
Practice: Personal Experiences, Public Issues Vol. 2, edited by Derek Colquhoun and Allan Kellehear, 95-113. London: Chapman and Hall.

Kroger, Jane. 2003. 'What Transits in an Identity Status Transition?' Identity: An International Journal of Theory and Research, 3 (3):197-220.

Litzinger, Ralph, A. 1998. 'Memory Work: Reconstituting the Ethnic in Post-Mao China'. Cultural Anthropology 13 (2):224-55.

Loomba, Ania. 2003. 'Dead Women Tell No Tales'. In Feminist Postcolonial Theory: A Reader, edited by Reina Lewis and Sara Mills, 241-63. New York and Oxon: Routledge.

Lorde, Audre. 1988. A Burst of Light, Essays. London: Sheba Feminist Publishers.

Maguire, Patricia. 1987. Doing Participatory Research: A Feminist Approach, Amherst, MA: University of Massachusetts.

Meyer, Morgan. 2012. 'Placing and Tracing Absence: A Material Culture of the Immaterial'. Journal of Material Culture 17 (1):103-10.

Misra, Joya, Jennifer Lundquist, Elissa Dahlberg Holmes, and Stephanie Agiomavritis. 2010. Associate Professors and Gendered Barriers to Advancement. Amherst, MA: University of Massachusetts. http://people.umass.edu/misra/Joya_Misra/ work-life_files/Associate\%2oProfessors\%20and\%2oGendered\%2oBarriers\%20 to $\% 20$ Advancement $\% 20$ Full\%2oReport.pdf

Mountz, Alison, Anne Bonds, Becky Mansfield, Jenna Loyd, Jennifer Hyndman, Margaret Walton-Roberts, Ranu Basu, Risa Whitson, Roberta Hawkins, Trina Hamilton, and Winifred Curran. 2015. 'For Slow Scholarship: A Feminist Politics of Resistance Through Collective Action in the Neoliberal University'. ACME: An International Journal for Critical Geographies 14 (4):1235-59.

Narayan, Kirin. 2012. Alive in the Writing: Crafting Ethnography in the Company of Chekhov. Chicago: University of Chicago Press.

O’Donoghue, Rob. 2006. 'Locating the Environmental in Environmental Education Research: A Review of Research on Nature's Nature, its Inscription in Language and Recent Memory Work on Relating to the Natural World'. Environmental Education Research 12 (3-4):345-57. 
Olick, Jeffrey K. 1999. 'Collective Memory: The Two Cultures'. Sociological Theory $17(3): 333-48$.

Onxy, Jenny, and Jennie Small. 2001. The Method of Memory-work'. Qualitative Inquiry 7 (6):773-86.

Ovens, Alan, and Richard Tinning. 2009. 'Reflection as Situated Practice: A Memory-work Study of Lived Experience in Teacher Education' Teaching and Teacher Education 25(8):1125-31.

Reinharz, Shulamit, and Lynn Davidman. 1992. Feminist Methods in Social Research. Oxford: Oxford University Press.

Schön, Donald A. 1983. The Reflective Practitioner: How Professionals Think in Action. New York: Basic Books.

Small, Jennie. 1999. 'Memory-work: A Method for Researching Women's Tourist Experiences'. Tourism Management 20 (1):25-35.

Small, Jennie, Candice Harris, Erica Wilson, and Irena Ateljevic. 2011. 'Voices of Women: A Memory-work Reflection on Work-Life Dis/harmony in Tourism Academia. Journal of Hospitality, Leisure, Sport and Tourism Education 10 (1):23-36.

Spindler, George, and Louise Spindler. 1993. 'The Process of Culture and Person: Cultural Therapy and Culturally Diverse Schools'. In Renegotiating Cultural Diversity in American Schools, edited by Patricia Phelan and Ann Locke Davidson, 21-51. New York: Teachers College.

Spronken-Smith, Rachel, Rebecca Stringer, and Cheryl A. Wilson. 2016. 'Gender, Academic Careers and the Sabbatical: A New Zealand Case Study'. Higher Education Research and Development 35 (3):589-603.

University of Auckland. 2014. University of Auckland Equity Profile. Auckland, New Zealand: University of Auckland. https://cdn.auckland.ac.nz/assets/auckland/ about-us/equity-at-the-university/plans-reports-reviews/university-of-auckland-equity-profile-2015.pdf

Youngs, Gillian. 2001. 'The Political Economy of Time in the Internet Era: Feminist Perspectives and Challenges'. Information, Communication and Society 4(1):1433. 